\title{
Effects of Using Artificial Intelligence Teaching System for Environmental Education on Environmental Knowledge and Attitude
}

\author{
Shien-Ping Huang ${ }^{1^{*}}$ \\ ${ }^{1}$ Department of Business Administration, China University of Science and Technology, Taipei City, TAIWAN, R.O.C.
}

Received 10 January 2018 - Revised 23 April 2018 • Accepted 13 May 2018

\begin{abstract}
The emergence of computers resulted in the application revolution to instruction; till the emergence of the Internet, the strong communication ability became the major role and fully developed the integration of technology and network. The emergence of artificial intelligence teaching systems really fulfilled leaner-centered learning. Based on learner needs, the design changed the learning interaction in automatic teaching from the interaction with machines to the interaction with knowledge. With quasiexperimental study, total 186 college students, as the research object, are proceeded 16 -week ( 3 hours per week for total 48 hours) environmental education with artificial intelligence teaching systems. The research results conclude significant correlations between 1.environmental education and environmental knowledge, 2.environmental knowledge and environmental attitude, and 3.environmental education and environmental attitude. According to the results, suggestions are proposed, expecting to reinforce the teaching ability of environmental education, cultivate college students' understanding of environment, enhance environmental protection knowledge, attitude, and action intention, as well as promote the skill to use environmental action strategies.
\end{abstract}

Keywords: artificial intelligence teaching system, environmental education, environmental knowledge, environmental attitude

\section{INTRODUCTION}

The emergence of computers resulted in the first application revolution of automatic instruction. The application presented the characteristic of computers being programmable. The emergence of the Internet, the automatic instruction with computers as the major teaching media, was the second application revolution of automatic instruction, in which computers became the supporting role, while the strong communication ability of the Internet became the major role. Education units in many countries realized the potential of network technology development, devoted to the application of network technology to instruction, and fully developed the integration of technology and network. The Internet, with the media characteristics of active knowledge exploration and huge users, immediately became a new battle for new and old automatic instruction technology. The emergence of artificial intelligence teaching systems really fulfilled the learner-centered learning. The learner need based design released the criticism of automatic instruction not stressing on human nature and changed the learning interaction in automatic instruction from the interaction with "machines" and "programs" to the interaction with "knowledge". With problem solving, artificial intelligence teaching systems did not simply provide "electronic books" with higher automation, but became the provider with high-quality one-to-one teaching environment.

When various countries largely developed the economy and accelerated the industry, the natural environment was seriously damaged to result in lots of environmental problems. Afterwards, people gradually concerned about environmental resources on the earth and realized that such resources should not be wasted. Some people were aware that environmental problems could be thoroughly solved merely by humans presenting keen awareness and

(C) 2018 by the authors; licensee Modestum Ltd., UK. This article is an open access article distributed under the terms and conditions of the Creative Commons Attribution License (http://creativecommons.org/licenses/by/4.0/). $\square$ huang@cc.cust.edu.tw (*Correspondence) 


\section{Contribution of this paper to the literature}

- Teachers, before engaging in related teaching, are suggested to acquire literature and network data related to environmental education, participate in relevant training activities, and interact with environmental protection related groups or people in order to broaden the professional knowledge and timely introduce to the courses to enrich the lessons.

- Environmental education as a part of formal education for college students receiving systematic environmental education, knowing environmental ecology, understanding the source of environmental pollution and the effect on life, and further cultivating the concept and behavior to protect the environment so as to benefit the success of environmental protection actions.

- To standardize the materials and describe the educational attributes, resource meanings, and general resource property of teaching materials.

brand-new understanding of the survival environment and cultivating the environmental action skills. Environmental education was the fundamental methods to promote environmental attitudes and environmental behaviors. By developing people's environmental knowledge and environmental value with environmental education to change the attitudes, people would naturally emphasize environmental issues and take beneficial behaviors for the environment, i.e. being responsible for the environment, particularly the environmental knowledge of the next generation and the habit to protect the environment. This study therefore precedes environmental education with artificial intelligence teaching systems to understand the effect on knowledge and attitude. It is expected to reinforce the teaching ability of environmental education, cultivate college students' understanding of environment, enhance the environmental knowledge, attitudes, and action intention, as well as promote the skills to use environmental action strategies.

\section{LITERATURE REVIEW}

\section{Artificial Intelligence Teaching System}

Lai (2016) simply defined artificial intelligence as a computer system with human knowledge and behaviors and solving problems, memorizing knowledge, and understanding human natural language through learning and reasoning. $\mathrm{Ng}$ (2016) described the generation of artificial intelligence (AI) as decomposing the processes of human stimuli and responses induced by problems and affairs as well as the reasoning, problem-solving, learning, judging, and thinking of decisions into basic steps and modularizing or formulating problem-solving processes through programming so that a computer could be designed with structural methods or cope with more complicated problems. Hwang, Kongcharoen, and Ghinea (2014) regarded an artificial intelligence teaching system as a computer-based teaching system which could simulate human teachers, detect learners' learning conditions, and determine what to teach, when to teach, and how to teach with AI technology. Ricoy and Feliz (2016) indicated that an artificial intelligence teaching system aimed to provide each college student with possible teaching assistance as one-to-one teaching from a senior teacher. To achieve such an objective, four independent elements of college student model, teaching module, domain knowledge, and interface module were designed. "Curriculum sequencing", "intelligent analysis of student's solutions" and "interactive problem-solving support" were adopted as the core technology. An emerging technology, "example-based problem-solving support", was added after 1990 (Lai \& Chen, 2014).

\section{Environmental Education}

Environmental education is the education process, aiming at the correlation between humans and the natural environment \& artificial environment, including population problems, pollution problems, energy allocation and conservation problems, natural conservation problems, technology development, traffic infrastructure, as well as urban and rural plans, to have the citizens understand the relationship with the environment through education (Sáez-López, Román-González, \& Vázquez-Cano, 2016). Cela, Sicilia, and Sánchez (2015) mentioned that environmental education was the process to recognize value and clarify concepts so as to cultivate necessary skills and attitudes for understanding and appreciating the interaction between humans, culture, creatures and physical environment. Environmental education should also be expanded to decision-making related to environmental quality and self-behavior regulations. Nikou and Economides (2017) regarded environmental education as the education process, in which individuals and the society knew the environment and interacted with the environment compositions of creatures, physical and social culture, acquired knowledge, skills, and value, and could individually or collectively solve environmental problems. de-Marcos et al. (2016) stated that environmental education was the education process aiming to improve the environment and the education process to clarify 
concepts and form value as well as necessary knowledge, skills, and attitudes for people understanding and experiencing the interactive relationship between humans and culture, creatures, physical. Environmental education also taught people to make decisions, when facing issues related to environment quality, and develop the principle for self-behaviors. Sheorey (2014) indicated that environmental education aimed to cultivate people in the world noticing the environment and the problem solving, concerning about the environment, presenting problem-solving capability on environmental problems, and being able to prevent from possible problems in the future. For this reason, every one or group in the world should be taught necessary knowledge, skills, attitudes, willingness, and practice abilities so as to acquire proper coping strategies to deal with and prevent from environmental problems.

The dimensions proposed by Dong, Zhang, Dai, and Guan (2014) are used for deeply discuss environmental education.

(1) Knowledge concept: Referring to the environment and the surrounding natural ecology, geomorphologic characteristics, environmental ecological cycle, pollution concepts, environment maintenance, and limit environmental resources.

(2) Affection concept: Referring to concerns about environment, appreciation of nature beauty, correct environmental ethics and value, and integration of environmental culture and art.

(3) Technical concept: Referring to the prevention of environmental pollution, water purification, development and management of environmental resources, conservation of environmental resources, and environmental protection behaviors.

\section{Environmental Knowledge}

Lee (2014) regarded environmental knowledge as individual understanding of the environment. Jeno, Grytnes, and Vandvik (2017) considered that environmental knowledge was an interdisciplinary subject, whose knowledge was induced by natural and social science and anthropology; sometimes, it involved in value and division of power and covered broadly, including food, clothing, housing, and transportation for human beings. Knowledge related to life and environment therefore could be regarded as environmental knowledge (Chou, Lunsford, \& Thomson, 2015; Hosseinnezhad, 2017). Environmental knowledge was generally referred to individual understanding of environmental affairs (Sarkar \& Petrova, 2013), with broad coverage. Park and Lee (2014) indicated that environmental knowledge contained 1. knowledge of environmental issues, 2 . knowledge related to environmental action strategies, and knowledge of action skills.

Referring to Lai and Hwang (2015), the following three dimensions are applied to environmental knowledge.

(1) Nature knowledge: Including issues of biology and ecology, e.g. compositions and functions of ecological systems, flow of materials and energy in ecological systems, ethnic groups and clusters, and effect of humans on ecological systems.

(2) Problem knowledge: Containing resources in natural environment and environmental problems caused by overuse of natural resources.

(3) Action strategy: Types of environmental actions, solving problems with proper actions, and skills to use environmental actions (Sllame \& Jafaray, 2013).

\section{Environmental Attitude}

Joo-Nagata, Abad, Giner, and García-Peñalvo (2017) referred "environmental attitude" to the compositions of special situations in the environment, the entire environment, or the belief of people or objects directly related environment. Such compositions contained the overall evaluation of for or against, like or dislike. PlanasLladó et al. (2014) regarded "environmental attitude" as college students' value of the entire environment, the opinions about humans' responsibilities and roles in the environment, individual perception of affairs related to environment with the emotional tendency of for or against, like or dislike, e.g. self-perception of the responsibility for the environment and the concerns about environment problems. Shadiev, Hwang, Huang, and Liu (2015) pointed out environmental attitude as the compositions of special situations in the environment, the entire environment, or people, affairs, and objects directly related to the environment. Such compositions included the overall evaluation of for or against and like or dislike (Darvin \& Norton, 2014). Accordingly, environmental attitude referred to individual opinions about the value of the entire environment and human responsibility and role in the environment (Vanderhoven et al., 2015).

Referring to Huang et al. (2014), the following dimensions are used for environmental attitude in this study.

(1) Environmental sensitivity: Referring to the seriousness of environmental problems and individual opinions about the relevance. The cultivation requires long-term natural experience or model guidance in life. 
(2) Environmental belief: Referring to individual ideas about the mutual relationship between humans and natural environment. It is divided into mainstream society model and new environment model.

(3) Environmental value: Referring to individual perceived value of environment and the relevant problems.

(4) Environmental ethics: Humans' belief in environmental ethics expands from individual to family, region, nation, human beings, creatures, inanimate objects, and the universe, i.e. expanding from "human-centered ethics" to "life-centered ethics" and to "ecology-centered ethics".

\section{Research Hypothesis}

In the study on the effect of environmental teaching on college students' environmental awareness, attitudes, and behaviors, $\mathrm{Xu}$, Huang, and Tsai (2014) concluded top five sources of environmental knowledge as television, newspaper, parents, teachers, and schools. Cela et al. (2015) indicated that senior college students mainly acquired ecological conservation knowledge from mass media or texts, followed by computer networks, teachers' lectures, and school courses. García-Saiz, Palazuelos, and Zorrilla (2014) mentioned that television and teachers' lectures were the major sources of water resource conservation knowledge for college students. Dong et al. (2014) proceeded environmental education with the environmental protection area, Sihcao Wildlife Reserve, and revealed that field trips, mass media, and lessons were the major knowledge sources for college students. Accordingly, environmental education activities arranged by teachers or schools could largely enhance college students' environmental knowledge (Sarkar \& Petrova, 2013). According to above literatures, the following research hypothesis is inferred in this study.

H1: Environmental education shows significant correlations with environmental knowledge.

Lai and Hwang (2015) pointed out the remarkable correlation between college students' environmental knowledge and attitudes toward oceans. Molano and Polo (2015) found out the notable correlation between environmental knowledge and environmental attitude of learners in public vocational training institution. Park and Lee (2014) discovered that college students with higher environmental knowledge presented more positive attitudes toward the environment. Yilmaz (2016) found out the significantly positive correlation between high school teachers' environmental sensitivity and environmental knowledge. Other researchers (Sáez-López et al., 2016) also discovered the positive correlation between environmental knowledge and environmental attitude of college students after receiving 4-8 week environmental courses or programs. Apparently, education behaviors could positively promote environmental knowledge and environmental attitude. Regarding the correlation between cognition and affection, Nikou and Economides (2017) stated that college instructors' environmental knowledge, cognition of environmental problems in Taiwan, environmental awareness, and cosmic belief appeared positive correlations with social value. Based on above studies, the following research hypothesis is inferred in this study.

H2: Environmental knowledge reveals remarkable correlations with environmental attitude.

Huang et al. (2014) pointed out the positive effect of designed environmental education on college students' "environmental attitude". Xu and He (2014) designed the course for river environmental education to effectively enhance the river conservation attitudes of college students in the experimental group, and the posttest mean remarkably outperformed the pretest mean. Shadiev et al. (2015) pointed out the better posttest performance on environmental attitude of college students in the experimental group than the pretest, i.e. environmental issue integrated environmental education being able to promote college students' environmental attitudes. Joo-Nagata et al. (2017) regarded the final goal of environmental education as to cultivate the citizens with environmental literacy so as to cultivate the basic knowledge of environment, promote problem-solving skills, and enhance environmental action participation and attitudes. Lee (2014) considered that the goal of environmental education should focus on college students being able to experience the environment and teach basic environmental knowledge between humans and environment, aiming to cultivate college students' attitudes toward environmental protection, reinforce environmental attitude education, and put it into practice to maintain environmental quality in daily life. According to above literatures, the following research hypothesis is proposed in this study.

H3: Environmental education presents notable correlations with environmental attitude.

\section{SAMPLE AND MEASURING INDICATOR}

\section{Research Sample and Object}

With quasi-experimental research, total 186 college students, as the research object, are proceeded 16-week (3 hours per week for total 48 hours) environmental education with artificial intelligence teaching systems. The research data are analyzed with computer statistics software and various hypotheses are tested. 


\section{Reliability and Validity Test}

Validity refers to the measuring tool being able to really measure the problems which a researcher really intends to measure. Generally speaking, validity is divided into content validity, criterion-related validity, and construct validity. The items in the questionnaire in this study are referred to domestic and international researchers, and, before the distribution of formal questionnaire, the pretest is preceded after discussing to the tutor that it presents certain content validity. Environmental education, environmental knowledge, and environmental attitude are tested the overall structural causality with linear structural relation model, and the data entry is based on the correlation coefficient matrix of above observation variables. The linear structural relation model analysis results reveal the overall model fit reaching the rational range that it shows favorable convergent validity and predictive validity. Item-to-total correlation coefficients are used for testing the construct validity of the questionnaire content, i.e. reliability analysis. The calculated item-to-total correlation coefficients are utilized for judging the questionnaire content. The item-to-total correlation coefficients of the dimensions in this study are higher than 0.5, revealing certain degree of construct validity.

Reliability and validity analyses are further preceded. The higher Cronbach's a shows the better reliability. The Cronbach's a higher than 0.7 presents high reliability, while the Cronbach's a lower than 0.35 should be eliminated, and the value in 0.7 0.98 is regarded as high reliability. Moreover, item-to-total correlation coefficients should be higher than 0.4 , and those not conforming to the standard should be deleted. The formal questionnaire in this study is developed according to above standards, and the measured Cronbach's a appears in 0.70 0.80, obviously conforming to the reliability range.

Furthermore, discriminant validity would test the discrimination among dimensions with the square root of average variance extracted of individual dimension and the correlation coefficients of other dimensions. When the former is larger, the model shows discriminant validity. Accordingly, the square root of average variance extracted of "environmental education", "environmental knowledge", and "environmental attitude" are calculated, which are further compared with the correlation coefficients of dimensions. Apparently, the dimensions in this research model present discriminant validity.

\section{ANALYSIS OF EMPIRICAL RESULT}

\section{LISREL Model Assessment Indicator}

LISREL (linear structural relation) model combines factor analysis and path analysis in traditional statistics with simultaneous equations in econometrics that it could calculate multiple factors and multiple causal paths. The model fit could be evaluated from preliminary fit criteria, overall model fit, and fit of internal structure of model.

The research data are organized in Table 1. Preliminary fit criteria, fit of internal structure of model, and overall model fit are explained as below.

From Table 1, the dimensions of environmental education (knowledge concept, affection concept, technical concept) could significantly explain environmental education $(t>1.96, p<0.05)$, the dimensions of environmental knowledge (nature knowledge, problem knowledge, action strategy) could remarkably explain environmental knowledge $(t>1.96, p<0.05)$, and the dimensions of environmental attitude (environmental sensitivity, environmental belief, environmental value, environmental ethics) could notably explain environmental attitude $(t>1.96, p<0.05)$. Apparently, the overall model in this study shows favorable preliminary fit criteria.

In terms of fit of internal structure of model, environmental education presents positive and significant correlations with environmental knowledge (0.866), environmental knowledge shows positive and remarkable correlations with environmental attitude (0.883), and environmental education reveals positive and notable correlations with environmental attitude $(0.871)$ that $\mathrm{H} 1, \mathrm{H} 2$, and $\mathrm{H} 3$ are supported.

In regard to overall model fit, the standards $\chi^{2} / \mathrm{Df}=1.462$, smaller than the standard $3, \mathrm{RMR}=0.007$ show the appropriateness of $\chi 2 / D F$ and RMR. Besides, chi-square is sensitive to sample size that it is not suitable for directly judging the fit. The overall model fit standards GFI=0.934 and AGFI=0.904 are higher than the standard 0.9 (the closer GFI and AGFI to 1 revealing the better model fit) that the model shows better fit indices. 
Table 1. Analysis result of overall linear structural relation model

\begin{tabular}{|c|c|c|c|c|}
\hline evaluation item & parameter/evaluation sta & ard & result & $\mathbf{t}$ \\
\hline \multirow{10}{*}{ preliminary fit criteria } & \multirow{3}{*}{ environmental education } & knowledge concept & 0.683 & $9.88^{\star *}$ \\
\hline & & affection concept & 0.672 & $9.16^{* \star}$ \\
\hline & & technical concept & 0.694 & $10.79^{\star \star}$ \\
\hline & \multirow{3}{*}{ environmental knowledge } & nature knowledge & 0.637 & $7.46^{\star *}$ \\
\hline & & problem knowledge & 0.642 & 7.91 ** \\
\hline & & action strategy & 0.651 & $8.22^{\star *}$ \\
\hline & \multirow{4}{*}{ environmental attitude } & $\begin{array}{l}\text { environmental } \\
\text { sensitivity }\end{array}$ & 0.702 & $8.92^{\star *}$ \\
\hline & & environmental belief & 0.697 & $11.02^{\star \star}$ \\
\hline & & environmental value & 0.687 & $10.14^{\star \star}$ \\
\hline & & environmental ethics & 0.711 & 13.31 \\
\hline \multirow{3}{*}{$\begin{array}{l}\text { fit of internal structure } \\
\text { of model }\end{array}$} & \multicolumn{2}{|c|}{ environmental education $\rightarrow$ environmental knowledge } & 0.866 & $22.45^{\star *}$ \\
\hline & \multicolumn{2}{|c|}{ environmental knowledge $\rightarrow$ environmental attitude } & 0.883 & $27.39^{\star \star *}$ \\
\hline & \multicolumn{2}{|c|}{ environmental education $\rightarrow$ environmental attitude } & 0.871 & $24.61^{* *}$ \\
\hline \multirow{5}{*}{ overall model fit } & \multicolumn{2}{|c|}{ Squared chi-square value/degree of freedom } & \multicolumn{2}{|c|}{1.462} \\
\hline & \multicolumn{2}{|l|}{ fit index } & \multicolumn{2}{|c|}{0.934} \\
\hline & \multicolumn{2}{|l|}{ adjusted fit index } & \multicolumn{2}{|c|}{0.904} \\
\hline & \multicolumn{2}{|l|}{ residual root mean square } & \multicolumn{2}{|c|}{0.007} \\
\hline & \multicolumn{2}{|l|}{ Standardized fit index } & \multicolumn{2}{|c|}{0.913} \\
\hline
\end{tabular}

Table 2. Test of hypothesis

\begin{tabular}{ccccc}
\hline research hypothesis & correlation & empirical result & $\mathbf{P}$ & result \\
\hline $\mathrm{H} 1$ & + & 0.866 & 0.00 & supported \\
\hline $\mathrm{H} 2$ & + & 0.883 & 0.00 & supported \\
\hline $\mathrm{H} 3$ & + & 0.871 & 0.00 & supported \\
\hline
\end{tabular}

\section{CONCLUSION}

The research results reveal positive and remarkable effects of environmental education on environmental knowledge and environmental attitude. The results show that environmental education with artificial intelligence teaching systems could obviously enhance college students' environmental knowledge and concepts, change the attitudes and concerns about environment, as well as promote the belief and perception of environment friendliness; besides, college students' insight and sensitivity to environmental pollution are obviously reinforced. From the aspect of artificial intelligence teaching systems, the intelligent behavior of a system is the information of teaching module, according to college students, matching with knowledge structure in the domain knowledge to determine proper teaching strategies as ruled and present the results with the interface for communicating the knowledge with the users. For the users, the final presentation of knowledge is extremely important. From the process of college students' environmental education with the artificial intelligence teaching system, college students feel the learning fun in the environmental education with artificial intelligence teaching systems and enhance the knowledge. In the learning situation of environmental education with artificial intelligence teaching systems, college students could positively participate in the discussion of environmental issues and concern about them, without being restricted to the dull environmental knowledge on textbooks. More importantly, environmental education with artificial intelligence teaching systems could have the courses be funnier and extend college students' creation of imagination so that they would like to be a part of it.

\section{RECOMMENDATIONS}

According to the research results and findings, practical suggestions are further proposed in this study.

1. Under multiple environmental issues and diverse environmental protection, existing knowledge could no long cope with the changeable environmental problems. Teachers, before engaging in related teaching, are suggested to acquire literature and network data related to environmental education, participate in relevant training activities, and interact with environmental protection related groups or people in order to broaden the professional knowledge and timely introduce to the courses to enrich the lessons.

2. It is suggested to regard environmental education as a part of formal education for college students receiving systematic environmental education, knowing environmental ecology, understanding the source of environmental pollution and the effect on life, and further cultivating the concept and behavior to protect 
the environment so as to benefit the success of environmental protection actions. Moreover, teachers should flexibly apply distinct teaching strategies with artificial intelligence teaching systems and stress on college students' individual differences so that college students could easily understand the environmental education content and present higher learning interests to make environmental education be more effective.

3. To have artificial intelligence teaching systems present the maximal flexibility to reconstruct material knowledge, according to the teaching module, the knowledge structure in domain knowledge presents the critical status. It is therefore suggested to standardize the materials and describe the educational attributes, resource meanings, and general resource property of teaching materials. In this case, any materials conforming to the same standards could be easily retrieved the education related information with the artificial intelligence teaching system, including learning concepts and the relationship with other concepts. It would not only solve the problem of speed for developing artificial intelligence teaching systems, but would also achieve the objectives of material sharing and repeated use.

\section{REFERENCES}

Cela, K. L., Sicilia, M. Á., \& Sánchez, S. (2015). Social network analysis in e-learning environments: A Preliminary systematic review. Educational Psychology Review, 27(1), 219. https:/ / doi.org/10.1007/s10648-014-9276-0

Chou, T.-S., Lunsford, P. J., \& Thomson, K. (2015). Design of Simulation-Based Laboratories for Teaching Wireless Network Technologies.

Darvin, R., \& Norton, B. (2014). Transnational identity and migrant language learners: The promise of digital storytelling. Education Matters: The Journal of Teaching and Learning, 2(1).

de-Marcos, L., García-López, E., García-Cabot, A., Medina-Merodio, J. A., Domínguez, A., Martínez-Herráiz, J. J., \& Diez-Folledo, T. (2016). Social network analysis of a gamified e-learning course: Small-world phenomenon and network metrics as predictors of academic performance. Computers in Human Behavior, 60, 312-321. https://doi.org/10.1016/j.chb.2016.02.052

Dong, Y., Zhang, X., Dai, J., \& Guan, H. (2014). HYVI: a hybrid virtualization solution balancing performance and manageability. IEEE Transactions on Parallel and Distributed Systems, 25(9), 2332-2341. https://doi.org/10.1109/TPDS.2013.239

García-Saiz, D., Palazuelos, C., \& Zorrilla, M. (2014). Data mining and social network analysis in the educational field: An application for non-expert users. In Educational Data Mining (pp. 411-439). Springer International Publishing. https://doi.org/10.1007/978-3-319-02738-8_15

Hosseinnezhad, F. (2017). A Study of the New Environmental Paradigm Scale in the Context of Iran. European Journal of Sustainable Development Research, 1(2), 14. https:// doi.org/10.20897/ ejosdr.201714

Huang, T.-Y., Jeyakumar, V., Lantz, B., Feamster, N., Winstein, K., \& Sivaraman, A. (2014). Teaching computer networking with mininet. Paper presented at the ACM SIGCOMM.

Hwang, W.-Y., Kongcharoen, C., \& Ghinea, G. (2014). To enhance collaborative learning and practice network knowledge with a virtualization laboratory and online synchronous discussion. The International Review of Research in Open and Distributed Learning, 15(4). https:/ / doi.org/10.19173/irrodl.v15i4.1805

Jeno, L. M., Grytnes, J. A., \& Vandvik, V. (2017). The effect of a mobile-application tool on biology students' motivation and achievement in species identification: A Self-Determination Theory perspective. Computers E Education, 107, 1-12. https:/ / doi.org/10.1016/j.compedu.2016.12.011

Joo-Nagata, J., Abad, F. M., Giner, J. G. B., \& García-Peñalvo, F. J. (2017). Augmented reality and pedestrian navigation through its implementation in m-learning and e-learning: Evaluation of an educational program in Chile. Computers $\mathcal{E}$ Education, 111, 1-17. https:/ / doi.org/10.1016/j.compedu.2017.04.003

Lai, C. L., \& Hwang, G. J. (2015). An interactive peer-assessment criteria development approach to improving students' art design performance using handheld devices. Computers $\mathcal{E}$ Education, 85, 149-159. https://doi.org/10.1016/j.compedu.2015.02.011

Lai, C. Y. (2016). Training nursing students' communication skills with online video peer assessment. Computers $\mathcal{E}$ Education, 97, 21-30. https:/ / doi.org/10.1016/j.compedu.2016.02.017

Lai, H. M., \& Chen, T. T. (2014). Knowledge sharing in interest online communities: A comparison of posters and lurkers. Computers in Human Behavior, 35, 295-306. https:/ / doi.org/10.1016/j.chb.2014.02.004

Lee, L. (2014). Digital news stories: building language learners' content knowledge and speaking skills. Foreign Language Annals, 47(2), 338-356. https:/ / doi.org/10.1111/flan.12084

Molano, S., \& Polo, A. (2015). Social Network Analysis in a Learning Community. Procedia-Social and Behavioral Sciences, 185, 339-345. https:/ / doi.org/10.1016/j.sbspro.2015.03.381 
$\mathrm{Ng}$, E. M. (2016). Fostering pre-service teachers' self-regulated learning through self-and peer assessment of wiki projects. Computers $\mathcal{E}$ Education, 98, 180-191. https:// doi.org/10.1016/j.compedu.2016.03.015

Nikou, S. A., \& Economides, A. A. (2017). Mobile-based assessment: Investigating the factors that influence behavioral intention to use. Computers $\mathcal{E}$ Education, 109, 56-73. https:/ / doi.org/10.1016/j.compedu.2017.02.005

Park, J. G., \& Lee, J. (2014). Knowledge sharing in information systems development projects: Explicating the role of dependence and trust. International Journal of Project Management, 32(1), 153-165. https:/ / doi.org/10.1016/j.ijproman.2013.02.004

Planas Lladó, A., Soley, L. F., Fraguell Sansbelló, R. M., Pujolras, G. A., Planella, J. P., Roura-Pascual, N., ... Moreno, L. M. (2014). Student perceptions of peer assessment: an interdisciplinary study. Assessment $\mathcal{E}$ Evaluation in Higher Education, 39(5), 592-610. https:/ / doi.org/10.1080/02602938.2013.860077

Ricoy, M. C., \& Feliz, T. (2016). Twitter as a learning community in higher education. Journal of Educational Technology \& Society, 19(1), 237.

Sáez-López, J. M., Román-González, M., \& Vázquez-Cano, E. (2016). Visual programming languages integrated across the curriculum in elementary school: A two year case study using "Scratch" in five schools. Computers E Education, 97, 129-141. https:/ / doi.org/10.1016/j.compedu.2016.03.003

Sarkar, N. I., \& Petrova, K. (2013). Design and evaluation of a web-based tool for teaching computer network design to undergraduates. Web-Based and Blended Educational Tools and Innovations, 214-231. https:// doi.org/10.4018/978-1-4666-2023-0.ch014

Shadiev, R., Hwang, W.-Y., Huang, Y.-M., \& Liu, T.-Y. (2015). The Impact of Supported and Annotated Mobile Learning on Achievement and Cognitive Load. Educational Technology E Society, 18(4), 53-69.

Sheorey, T. (2014). Empirical evidence of relationship between virtual lab development and students learning through field trials on vlab on mechatronics. International Journal of Information and Education Technology, 4(1), 97. https:/ / doi.org/10.7763/IJIET.2014.V4.377

Sllame, A. M., \& Jafaray, M. (2013). Using Simulation and Modeling Tools in Teaching Computer Network Courses. Paper presented at the IT Convergence and Security (ICITCS), 2013 International Conference on. https:/ / doi.org/10.1109/ICITCS.2013.6717895

Vanderhoven, E., Raes, A., Montrieux, H., Rotsaert, T., \& Schellens, T. (2015). What if pupils can assess their peers anonymously? A quasi-experimental study. Computers $\mathcal{E}$ Education, 81, 123-132. https:/ / doi.org/10.1016/j.compedu.2014.10.001

Xu, L., \& He, W. (2014). Networked Learning Community Construction Based on Instant Messaging Software. In Advanced Materials Research (Vol. 971, pp. 1663-1666). Trans Tech Publications. https:/ / doi.org/10.4028/www.scientific.net/AMR.971-973.1663

Xu, L., Huang, D., \& Tsai, W.-T. (2014). Cloud-based virtual laboratory for network security education. IEEE Transactions on Education, 57(3), 145-150. https:/ / doi.org/10.1109/TE.2013.2282285

Yilmaz, R. (2016). Knowledge sharing behaviors in e-learning community: Exploring the role of academic selfefficacy and sense of community. Computers in Human Behavior, 63, 373-382. https://doi.org/10.1016/j.chb.2016.05.055

\section{http://www.ejmste.com}

